\title{
Projects: A Technique for EFL
}

Chris Hawes

Teachers who work overseas often find that many of the techniques they used successfully in a Canadian context often fail when used with EFL students. The underlying problem is all too often that of motivation. In countries where English is neither the official language nor the lingua franca, students seldom see the need for learning the language. Even when teachers do manage to pique their students' interest by using activities based on information gaps, paired practice or shared group work, students will usually spend most of their time using the native language. Added to this, particularly in developing countries, are large classes, limited contact time (usually less than 200 minutes per week) with no chance for outside follow-up, and official policies which relegate English to a position of secondary importance, all of which conspire to maintain the students' lack of interest in the subject.

While the teacher can do little to change institutional problems, one technique that holds promise for increasing student motivation is the use of projects. In this case a project is any series of activities which are integrated so as to lead students to the achievement of a tangible goal, usually in the form of a concrete product such as a book, a newsletter or an audiotape. With a project the teacher teaches the language needed to accomplish each task along the way and the students apply the language so as to produce something concrete and visible, a physical manifestation of their learning. Projects motivate students because they provide a reason for learning the language (i.e., the language becomes a vehicle for accomplishing the project) and they are realizable within a relatively short period of time. If properly planned and orchestrated, a project not only increases motivation but also gives a sense of direction to the language learning.

For the sake of illustration, consider the following examples, all of which are unified around one of the simplest ways of implementing a project: having senior students produce materials for junior students:

Listening Tapes. Senior students are asked to prepare a tape or set of tapes that the teacher can use for teaching listening comprehension to junior students. Students then prepare short passages either by writing the passage themselves or by locating a suitable passage in a storybook or textbook. Next, students rehearse the passage under the teacher's correc- 
tive guidance (watching for such things as pronunciation problems) and then narrate the passage onto a cassette. This activity can be carried one step further by having students prepare accompanying comprehension questions.

A Language Handbook. Senior students confront the question, "What should a beginning student learn?" and then organize themselves so as to produce a handbook.

Biographies. After a lot of preparatory work (i.e., reading and discussing biographies, formulating appropriate questions, pronunciation practice, notetaking, students interviewing one another), senior students are asked to interview English speakers in the school or in the outside community and then write a biography of that person. Biographies are then selected, edited and corrected by a panel and reproduced as a "Who's Who In __. The selected biographies are then used as reading passages for junior students.

Other examples abound and are not confined to senior students: cultural fables and stories, individual or team writing contributions to annual school magazines, inter-class debates, plays or variety shows and interschool letter writing exchanges. In all cases a project's central feature remains constant $-\mathrm{a}$ tangible and realizable goal that can be demonstrated as a finished product.

Teachers who are interested in implementing a project in their EFL class should keep in mind the following guidelines and suggestions:

Project Appropriateness. A project must be of interest to the students involved. Likewise, students must recognize a real value in what they are doing. Producing materials for junior students is an example of this consideration. Older students could even be involved in the decision making process.

Communicative Transferability. The activities that comprise a project, and the language used should have, whenever possible, transfer value to other situations. The interview phase of the Biography Project is based on this consideration as students must use questions that are common to interpersonal communication (e.g., family, background). Likewise, follow-up activities should make the link between the two clear.

Phasing and Sequencing. Have all the necessary steps needed to accomplish the project been considered? What prerequisite skills do the students need? What does the teacher need to teach?

Teacher's Role. Teachers should act as facilitators and resource persons, intervening only at the crucial points needed to ensure quality. The teacher's corrective guidance during the rehearsal phase of the Listening Tapes Project is an example of such a crucial point where the teacher must intervene. Nonetheless, students should be given the freedom needed to 
explore and create, if not with the language used then at least with the product's final design and arrangement.

Quality Product. The finished product should be of high quality otherwise the students' hard work and perseverance are demeaned. In the case of printed material this means good quality reproduction, accompanying pictures or other visuals, a title page, table of contents or whatever else is appropriate.

\section{Conclusion}

Projects, conducted within this framework, is one technique that may increase student motivation and help EFL teachers make the best of an imperfect situation.

\section{THE AUTHOR}

Chris Hawes is an ESL teacher who has worked around the world. For the last two years he has worked for CUSO in both Nigeria and Malaysia, both as a classroom teacher and as a Special Programme Assistant for a teacher-upgrading programme. 